die zur Feststellung der Formel überbleibenden Mengen von Kalk, Borsäure und Wasser für sich auf die procentische Zusammensetzung erhoben, so ergiebt dies:

Gefunden

\begin{tabular}{|c|c|c|c|c|c|}
\hline A. & & $B$. & & $0=10$ & Berechnet \\
\hline 10,853 & - & 10,960 & - & 35,1651 & $-10,916$ \\
\hline 54,306 & - & 53,505 & -4 & $174,4816^{\circ}$ & 54,162 \\
\hline 34,841 & - & 35,535 & -10 & 112,5000 & 34,922 \\
\hline 100,000 & & 0,000 & & 1467 & 000. \\
\hline
\end{tabular}

Dass bei den nicht unbeträchtlichen Mengen dieser Mineralien, wie sie jetzt in den Handel kommen, sie eine Bedeutung für die Darstellung der Borgäure etc. gewinnen, bedarf wohl nur der Erwähnung.

\title{
Samaderin, ein neuer Körper aus Samadera indica Gärtn.
}

(Aus dem Holländischen von Dr. Johannes Müller in Berlin.)

Die Samadera indica Gärtn. (Vithmannia elliptica Vahl), von den Malayen Gatip Pahit genannt, ist ein auf Java in der Residentschaft Bautam vorkommender Baum, welcher zu der Classe der 'Terebinthineen und zur Ordnung der Simarubeen nach Bartling gezählt wird. Von C. L. Blume, der augenblicklich auf Java weilt, ist er näher beschrieben, jedoch in chemischer Beziehung noch unbekannt, da Rochleder in seiner Phytochemie, Seite 39, wo dio Pflanze unter den Simarubeen steht, nur davon sagt, dass die Wurzel, Rinde und Blätter sehr bitter seien.

Der Baum zeichnet sich besonders durch die vielen Früchte aus, welche in lederartigen Schalen eingeschlossen, die Form der Mandeln haben und ein Gewicht von 11/5 Grm. besitzen. Sie sind sehr reich an Oel und zeichnen sich ebenso wie die Rinde des Baumes durch einen sehr bittern Geschmack aus. Dieses Bitter ist, man kann wohl sagen: das Bitterste im ganzen 
266 Samaderin, neuer Körper aus Samadera indica Gärin.

Pflanzenreiche, und wird von keinem andern bis jetzt bekannten Bitterstoffe übertroffen. Diesem Umstande verdanken wir die vorläufige Untersuchung, zu der Herr Rost von Tonningen zu Buitenzorg (Ohnesorgen) auf Java das Material lieferte, die jedoch in grösserem Maassstabe erfolgen wird, sobald eine grössere Menge der Rinde und Früchte eingesammelt und besorgt sind.

100 Theile der Früchte und der Rinde von Samadera indica enthalten:

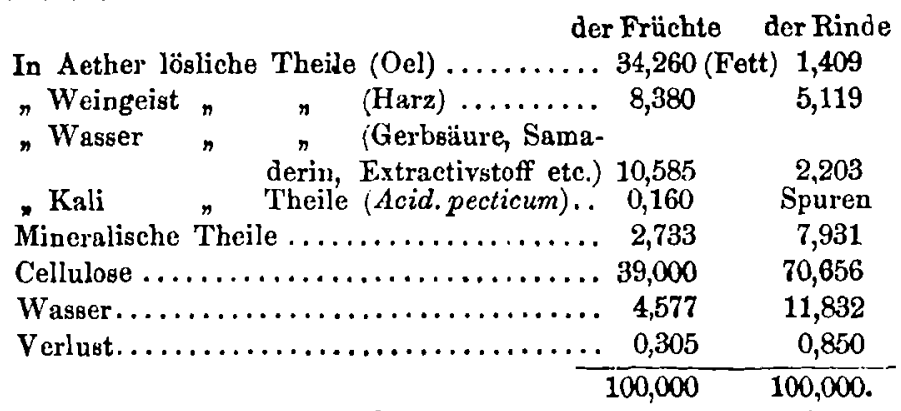

Die Eigenschaften dieser Körper waren folgende:

Der Frulchte.

Das Oel ist farblos, besitzt einen eigenthümlichen Geruch, keinen bekannten Geschmack und ist leichter als Wasser, es brennt mit gelblich-weisser, alsdann rother Flamme und bildet mit Alkalien Seifen.

Das Harz ist eine braune sehr bitter schmeckende Substanz, welche schnell Feach-
Der Rinde.

Das Fett ist hellgelb, reagirt neutral und besitzt: olartigen bittern Geschmack (verursacht durch etwas in dem nicht ganz wasserfreien Aether aufgelöstes Samaderin), ist ferner von weicher harzartiger Consistenz und lässt sich in Fäden ziehen. Durch Laugen wird es nur theilweise verseift und besteht aus einem Gemenge von Fett und einem harz. artigen Körper.

Das Harz kommt fast mit dem der Früchte überein, nur giebt die wässerige $\theta$ 
Samaderin, neuer Körper aus Samadera indica Gürtn. 267

Der Frilchte.

tigkeit aus der Luft anzieht und darauf zerfliesst. Durch Wasser wird ein wenig aufgelöst und diese Auflösung giebt mit Eisenchlorid einen schwarz. Niederschlag (Gerbsäure). Erwärmt schmilit es, blähet sich auf und verbrennt sehr leicht unter Verbreitung eines harzartigen Geruchs, eine hellgraue Asche zurücklassend, die in Wasser fast ganz unlöslich ist. Sie besteht zum grössten Theile aus Chlorverbindungen von Kalk und Kali mit Spuren von Eisen.

Die in Wasser lös. lichen Theile sind hellbraun gefärbt und lassen nach dem Verdampfen ein Extract zurück, welches an der Luft zerfliesst. Sie sind so bitter, als die weingeistigenAuszüge, und bestehen aus einem Gemenge von Extractivstoff, Zucker, Gerbsäure und Samaderin.

Die Asche, welche sie nach dem Verbrennen zurücklassen, braust mit Säure stark auf und besteht grösstentheils aus Chlorverbindungen von Kalk und Kali.

Die Mineraltheile lösen sich in Wasser theil-
Der Rinde.

Auflösung mit Eisenchlorid einen viel stärkeren Niederschlag, als bei den Früchten.
Die in Wasser löslichen Theile der Rinde hatten dieselben Eigenschaften, wie die der Früchte.
Die Mineraltheile enthalten Kieselerde, Eisen. 
268 Samaderin, neuer Körper aus Samadera indica Crärtn.

Der Fruchte.

weise auf, welche Auflösung alkalisch reagirt; sie bestehen vorzüglich aus Chlorverbindungen des Kalkes und des Kalis.
Der Rinde.

oxyd und unterscheiden sich vor allem durch einen grossen Gehalt an Chlorkalium, welches aus der Auflösung der Rinde in Wasser beim Verdampfen und Abkuihlen krystallisirt.

Der wichtigste Bestandtheil der Rinde und der Frïchte der Samadera indica ist ohne $Z_{w}$ eifel das darin enthaltene Samaderin. Die erhaltene Probe war nur leider nicht eine solche Quantität, dass man damit eine umfassende Untersuchung hätte vornehmen können. Es wird erhalten durch Abdampfen des wässerigen Auszuges der Rinde und Früchte zur Extractconsistenz, welche mit kleinen Mengen Alkohol wiederholt behandelt wird und wodurch der grösste Theil von Samaderin zurückbleibt. Durch Auflösung in Wasser und Behandlung mit Thierkohle kann man es rein erhalten.

Das Samaderin ist glänzend weiss von Farbe, blattförmig, etwas federartig, krystallinisch. Der Geschmack ist so anhaltend und intensiv bitter, wie mir noch kein anderer Körper vorgekommen ist. Beim Erhitzen schnilzt es und verbreitet Dämpfe, welche eingeathmet, einen bittern scharfen Geschmack besitzen, während es bei fortgesetztem Erhitzen verkohlt und wegbrennt, ohne eine Spur von Asche zurückzulassen.

In Wasser löst es sich leichter als in Alkohol, diese Aufösungen reagiren vollständig neutral. Auf Kaliumeisencyanid, schwefels. Kupferoxyd, salpeters. Silberoxyd, Chlorplatin, Jodtinctur, schwefels. Eisenoxydul, Eisenchlorid und chromsaures Kali übt es nicht die mindeste Reaction aus. Durch Salpetersäure und Chlorwasserstoffsäure wird es gelb gefürbt, während durch Zusatz von concentrirter Schwefelsäure sogleich eine prächtige roth-violette Färbung entsteht, welche mit der Zeit verschwindet und eine Masse federartiger, stark irisiren- 
der Krystalle zurücklässt, die später noch näher untersucht werden sollen.

Das Samaderin kann man zu der Reihe indifferenter, krystallisirbarer organischer Körper rechnen, zu welchen Salicin, Phloridzin und andere gehören. Sobald eine grössere Menge dargestellt sein wird, sollen die weiteren Untersuchungen veröffentlicht werden; alsdann wird auch die Frage gelöst werden, ob das Samaderin, welches mit Schwefelsäure cine so charakteristische Reaction giebt, ebenso wie Salicin und Phloridzin dadurch in eine andere Verbindung aus Traubenzucker umgesetzt wird.

\section{Die Böttger'sche Harnzuckerprobe; von \\ Dr. Grischow.}

Noch ein Wort über die Böttger'sche Harnzuckerprobe, welcher der übrigens von mir hochgeschiitzte Autor

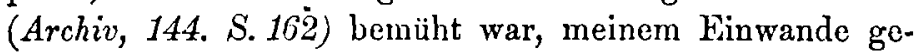
genüber (Arcliv, 141. S. 281) die behauptete Unfehlbarkeit zu vindiciren, welche denn doch in dem Urtheil liegt, „dass ausser dem IIarnzucker kein anderer Harnbestandtheil die geschilderte reducirende Einwirkung auf basisches Bismuthnitrat (in Verbindung mit kohlensaurem Natron) ausübe".

A. d. a. O. habe ich erwähnt, wie die in Rede stehende Böttger'sche Beobachtung mich lebhaft interessirt; will indess nicht verhehlen, dass die eben gedachte so entschiedene Behauptung in Betreff einer Flüssigkeit, die durch ungemein viel Zufälligkeiton so leicht ganz unerwartete, zufällige, leicht möglicher Weise auch mit reducirender Eigenschaft begabte Bestandtheile enthalten kann, von vornherein mir doch sehr gewagt erschienen ist. Natürlich, dass auch die sobald durch meine Beobachtungen erfolgte Bestätigung dieser meiner zweifelvollen Meinung für mich von Interesse war. 